\title{
Effect of feeding cows in early lactation with diets differing in roughage-neutral detergent fiber content on intake behavior, rumination, and milk production
}

\author{
G. Adin, ${ }^{*}$ R. Solomon, ${ }^{*}$ M. Nikbachat, $†$ A. Zenou,† E. Yosef, $†$ A. Brosh,† A. Shabtay,† S. J. Mabjeesh,† \\ I. Halachmi, $†$ and J. Miron ${ }^{1}$ \\ *Department of Cattle Husbandry, Extension Service, Ministry of Agriculture, PO Box 28, Bet-Dagan, 50250, Israel \\ †Department of Dairy and Genetic Science, Institute of Animal Science, Agricultural Research Organization, PO Box 6, Bet-Dagan, 50250, Israel \\ ‡Department of Animal Science, Faculty of Agriculture, The Hebrew University of Jerusalem, PO Box 12, Rehovot, 76100, Israel
}

\section{ABSTRACT}

This study measured the effects of including soyhulls as partial roughage replacement in total mixed rations (TMR) fed to 25 pairs of cows during early lactation, on the dry matter (DM) intake, particle kinetics, rumination, in vivo DM and NDF digestibility, milk and FCM yields, and BW changes. The 2 diets used in this study differed in the content of roughage and roughage NDF [23.5 vs. $35.0 \%$, and 12.8 vs. $18.7 \%$ in the experimental (EXP) and control (CON) TMR, respectively]. The EXP TMR contained 20.5\% less physically effective NDF than the CON TMR (11.7 vs. $14.1 \%$ of DM, respectively). These differences were expressed in a greater intake per meal (by 13.3\%), a higher rate of meal intake (by $23.2 \%$ ), a similar number of meals per day, a shorter daily eating duration (by $13 \%$ ), and a higher total daily DMI (by $7.2 \%$ ) in the EXP cows as compared with the CON cows. The in vivo DM and NDF digestibility was higher by 4.9 and $22.7 \%$, respectively, in the EXP cows than in the CON cows. The rumination time for the TMR in the EXP cows was $12.7 \%$ (54.3 $\mathrm{min} / \mathrm{d})$ shorter than in the CON cows, and this was probably related to the difference of $12.4 \%$ in physically effective NDF intake between the 2 groups. Patterns of daily rumination and feed consumption throughout an average day showed a delay of approximately 1 to $2 \mathrm{~h}$ between the eating and rumination peaks. Particle flow from the rumen of the EXP cows was characterized by a longer rumen mean retention time (by 17.8\%) and longer rumination time per kilogram of roughage ingested (by 23.5\%) as compared with the CON cows. Thus, favorable conditions for NDF digestion were created in the rumen of the EXP cows, as reflected in their rumen $\mathrm{pH}$ values (6.67). The advantage of the EXP cows in intake and

Received January 26, 2009.

Accepted March 21, 2009

${ }^{1}$ Corresponding author: jmiron@volcani.agri.gov.il digestibility was reflected in a concomitant increase of $7.4 \%$ in milk production and of $9.2 \%$ in FCM yield as compared with the CON cows. No difference was found between the 2 groups with respect to efficiency of feed utilization for milk production and BW changes.

Key words: early-lactating cow, dry matter and neutral detergent fiber digestibility, eating behavior, rumination

\section{INTRODUCTION}

In the early-lactation phase of high-yielding cows, maximum DMI delays behind the peak in milk production and may therefore result in a negative energy balance. The low DMI may be partially explained by the radical shift from a high-roughage ration fed during the dry period to a more energetic, low-roughage TMR fed immediately after calving, accompanied by the physiological and hormonal changes usually occurring in this period. According to NRC (2001), a fresh cow (up to $21 \mathrm{DIM}$ ) is able to consume nearly $18.5 \mathrm{~kg}$ of DM daily, and is therefore unable to supply the energy requirements for milk production and is compelled to mobilize the missing energy sources from body reservoirs.

Despite the large energy requirements in the early stage of lactation, it is not recommended that the energy density of the TMR be increased by addition of starchy grains (NRC, 2001) because of their possible inhibitory effect on cellulolytic microorganisms in the rumen, fiber digestibility, and dietary NDF utilization for milk and fat production. In addition, supplementation with grains might increase the risk of subacute rumen acidosis and other digestive disorders (Zebeli et al., 2007).

Recently, we suggested increasing the voluntary energy consumption of the lactating cow by replacing part of the dietary roughage component with by-products rich in readily digestible NDF, such as soyhulls (Miron et al., 2003). In previous studies (Miron et al., 2003, 2008; Adin et al., 2008), we demonstrated that feed- 
Table 1. Diet ingredients of the $2 \mathrm{TMR}^{1}$

\begin{tabular}{|c|c|c|}
\hline Ingredient, $\%$ of DM & EXP & $\mathrm{CON}$ \\
\hline Corn silage & 12.2 & 21.8 \\
\hline Vetch hay & 2.4 & 4.3 \\
\hline Wheat hay & 8.9 & 8.9 \\
\hline Soybean hulls & 14.5 & 0.0 \\
\hline Soybean meal (solvent extracted) & 4.5 & 4.5 \\
\hline Ground corn grain & 15.1 & 15.1 \\
\hline Ground barley grain & 13.1 & 13.1 \\
\hline Whole cottonseed & 4.4 & 4.4 \\
\hline Corn gluten feed & 6.6 & 6.6 \\
\hline Distillers dried grains & 6.6 & 6.6 \\
\hline Sunflower meal & 4.6 & 4.6 \\
\hline Rapeseed meal & 3.2 & 3.2 \\
\hline Wheat bran & 0.0 & 3.0 \\
\hline $\mathrm{NaHCO}_{3}$ & 0.7 & 0.7 \\
\hline $\mathrm{NaCl}$ & 0.4 & 0.4 \\
\hline $\mathrm{CaCO}_{3}$ & 1.2 & 1.2 \\
\hline $\mathrm{Ca}_{\mathrm{LCFA}}{ }^{2}$ & 1.0 & 1.0 \\
\hline Oil soapstock & 0.2 & 0.2 \\
\hline Urea & 0.3 & 0.3 \\
\hline Trace mineral-vitamin mixture ${ }^{3}$ & 0.1 & 0.1 \\
\hline Water, L/cow per d & 2.9 & 0.0 \\
\hline
\end{tabular}

${ }^{1} \mathrm{EXP}=$ experimental TMR containing $12.8 \% \mathrm{NDF}$ of roughage origin; $\mathrm{CON}=$ control TMR containing $18.7 \% \mathrm{NDF}$ of forage origin.

${ }^{2}$ Calcium salts of long-chain fatty acids.

${ }^{3}$ The trace mineral-vitamin mix contained (g/kg of DM): Zn, 24; Fe, $24 ; \mathrm{Cu}, 12.8 ; \mathrm{Mn}, 24 ; \mathrm{I}, 1.44$; Co, 0.32; Se, 0.32; vitamin A, 16,000,000 IU; vitamin $\mathrm{D}_{3}, 3,200,000 \mathrm{IU}$; vitamin $\mathrm{E}, 48,000 \mathrm{IU}$.

ing dairy cows with soyhulls during midlactation as a partial roughage replacement increased DMI by $6.9 \%$ and milk yield by $5.5 \%(P<0.05)$. However, there is a lack of knowledge on how the cow would respond to such a diet during the early stage of lactation. On the one hand, replacement of roughage with soyhulls might decrease the average TMR particle size and thus increase the rate of passage in the rumen and decrease its digestibility (Van Soest, 1994). On the other hand, soyhulls are potentially more digestible than roughage (Miron et al., 2003), and the decrease in particle size might increase the surface area available for the attachment of rumen cellulolytic bacteria (Miron et al., 2001), and thus might increase digestibility. It is not clear which trend is more predominant. Unfortunately, there are insufficient numbers of comprehensive studies in the literature dealing with the interactions among rate of particle passage in the rumen, in vivo digestibility, and rumination in high-producing dairy cows fed early-lactation diets differing in roughage content.

The objective of this study was to measure the effects of including soyhulls as a partial roughage replacement in TMR fed to cows during early lactation (until 90 DIM) on eating behavior, total DMI, particle kinetics along the gastrointestinal tract, patterns of rumination, in vivo digestibility of dietary DM and NDF, milk and FCM yields, and BW of the cows.

\section{MATERIALS AND METHODS}

\section{Cows, Diets, and Sampling Procedures}

Fifty Israeli Holstein cows were housed at the Agricultural Research Organization dairy farm, in 1 shaded corral with free access to water, during the winter season (November 2006 to March 2007). Cows were divided in pairs at the close-up period into 2 feeding groups similar in lactation number $(3.2 \pm 0.1$; mean $\pm \mathrm{SE}$ ) and milk production at the previous lactation $(11,960 \pm 227)$. After calving and during 90 DIM, the control cows (CON) were fed a TMR containing $18.7 \%$ roughage NDF, whereas the experimental cows (EXP) were fed a TMR that contained $12.8 \%$ roughage NDF and in which one-third of the dietary roughage was replaced by soyhulls (Table 1 ).

The 2 TMR were offered once daily at $1030 \mathrm{~h}$ for ad libitum intake, allowing for 5 to $10 \%$ orts, and the cows were milked 3 times daily at 0600, 1400, and 2200 h. Cows were fed individually via a computerized monitoring system designed to identify individual cows electronically and to control and record the daily feed intake of each cow automatically. The feeders were each mounted on weighing balances that enabled the monitoring of voluntary feed intake during every meal for each individual cow. A meal was defined as an identified cow visiting a feeder, with a visit lasting at least $2 \mathrm{~min}$ and in which at least $200 \mathrm{~g}$ of wet TMR was consumed. Once the electronic antenna located near the fodder registered a cow, feed intake and eating duration were measured for that meal and the number of meals per day, duration of each meal, and sum of intake were recorded. A description of this feeding system was given in a previous study (Miron et al., 2003). Voluntary daily DMI of the individual cows from calving to 90 DIM were determined based on DM content (AOAC, 2001) in daily sampled TMR and individual feed refusals.

The milk yield $(\mathrm{kg})$ of each cow was recorded daily by automatic meters (Afimilk, SAE Afikim, Kibbutz Afikim, Israel). Milk samples were collected during 3 sequential milkings on a weekly basis throughout the study. Each set of milk samples for each cow was stored at $4^{\circ} \mathrm{C}$ in the presence of a preservative tablet (2-bromo-2-nitropropane-1,3-diol, Bronopol; supplied by the Israeli Cattle Breeders Association, Caesaria, Israel) until analyzed for content of fat, protein, and lactose by infrared analysis (Israeli Cattle Breeders Association Laboratory, Caesaria, Israel, using a MilkoScan 4000 instrument, Foss Electric, Hillerød, Denmark). The yield of $4 \% \mathrm{FCM}$ was calculated using the following equation (NRC, 2001): $4 \% \mathrm{FCM}(\mathrm{kg})=0.4 \times$ milk $(\mathrm{kg})$ $+15.0 \times$ milk fat $(\mathrm{kg})$. 
Body weight data were recorded by an automatic walk-over scale 3 times a day while cows were entering the milking parlor. The animal performance study was carried out according to the guidelines and under the supervision of the Agricultural Research Organization Animal Care Committee.

\section{Chemical Analyses}

Replicate samples of the weekly composites of each TMR and of the orts of the individual cows were analyzed in triplicate for $\mathrm{DM}$ content (drying at $105^{\circ} \mathrm{C}$ for $24 \mathrm{~h}$ ) and residual ash $\left(4 \mathrm{~h}\right.$ at $\left.600^{\circ} \mathrm{C}\right)$. Dry TMR samples (dried at $60^{\circ} \mathrm{C}$ for $48 \mathrm{~h}$ ) were ground through a 1-mm sieve and analyzed for content of $\mathrm{CP}$ according to the Kjeldahl method or by ether extract (AOAC, 2001), and for the content of NDF (without sodium sulfite and with heat-stable $\alpha$-amylase), ADF, and acid detergent lignin according to Van Soest et al. (1991). An Ankom apparatus (Ankom ${ }^{220}$, Ankom Technology, Fairport, NY) was used for extracting and filtering the TMR and orts. The content of hemicellulose was determined as NDF - ADF, cellulose was determined as ADF acid detergent lignin, and lignin was determined as acid detergent lignin - residual ash.

The particle size distribution of the 2 TMR was determined by the New Penn State Forage Particle Separator (PSPS) system (Lammers et al., 1996). The physically effective NDF (peNDF) was determined as the proportion of DM retained by the 19- and the 8-mm sieves of the PSPS multiplied by dietary NDF content, as described by Yang et al. (2002).

\section{In Vitro Digestibility}

In vitro digestibility of DM and NDF in the weekly composites of the 2 TMR was analyzed in triplicate for each sample. The procedure involved incubating $0.5 \mathrm{~g}$ of dry TMR with rumen fluid for $48 \mathrm{~h}$ and then with 0.1 $N \mathrm{HCl}$ and $0.2 \%$ pepsin for another $48 \mathrm{~h}$, according to the 2-stage fermentation technique of Tilley and Terry (1963). Rumen fluid was obtained before the morning feeding via a rumen fistula from 3 dry cows fed a mixture of the CON and EXP diets. Residual NDF in the in vitro tubes was determined according to Van Soest et al. (1991). The rates of in vitro NDF degradability of the roughages in the TMR of this study, including corn silage, vetch hay, wheat hay, and soyhulls, were determined according to Mertens and Loften (1980).

\section{In Vivo Digestibility}

At wk 5 of the experiment, $6 \mathrm{~d}$ were assigned for daily sampling of TMR, feed refusals, and feces. Estimation of daily fecal excretion was based on indigestible NDF concentrations (used as an inner marker) in feces and TMR. Samples of the TMR and refusals were composited on a weekly basis, dried $\left(60^{\circ} \mathrm{C}\right.$ for $\left.48 \mathrm{~h}\right)$, and ground through a 1-mm sieve (Retsch S-M-100, Retsch, Haan, Germany). Fecal grab samples were taken twice daily for $6 \mathrm{~d}$, at 12-h intervals, with each day $2 \mathrm{~h}$ later than the preceding day. Fecal samples were composited (on a DM basis) for each cow during the collection period, dried at $60^{\circ} \mathrm{C}$ for $48 \mathrm{~h}$ in a forced-air oven, ground to pass through a 1-mm screen, and then used for the chemical analyses as described above. The indigestible NDF content was determined in the TMR and fecal samples according to the method of Lippke et al. (1986) and was used as an internal marker for the apparent total tract DM digestibility analysis. The digestibility of each chemical component of the ration was calculated for each cow by using the average individual DMI and fecal output.

\section{Rate of Passage}

The flow of TMR particles was measured in 5 pairs of cows ( 5 cows in each treatment) by oral administration of a single-dose marker (20 g, $\mathrm{Cr}_{2} \mathrm{O}_{3}$-impregnated paper; Ben-Ghedalia and Miron, 1984), followed by collection of individual fecal grab samples for a period of $7 \mathrm{~d}$ at $0,6,9,12,24,36,48,72,96,120,144$, and $168 \mathrm{~h}$ after marker administration. Fecal samples were collected and frozen until drying at $105^{\circ} \mathrm{C}$, and then ground through a 1-mm sieve. Chromium oxide content in the TMR and feces was determined by atomic-absorption spectrometry as described previously (Ben-Ghedalia and Miron, 1984). Transit time (h) was identified as the time from marker administration to its first appearance in the feces (Figure 1); rumen mean retention time (h) was identified as the time from the appearance of $5 \%$ of the dosed marker to the appearance of $80 \%$ of the marker in the feces (Figure 1); and rate of passage from the rumen and from the lower tract $(\% / \mathrm{h})$ were calculated according to Van Soest (1994) from the raw data given in Figure 1 and summarized in Table 4, based on the natural logarithms of fecal Cr concentrations against time as described by Ben-Ghedalia and Miron (1984).

\section{Rumen pH Measurement}

Once a week, 500-mL rumen fluid samples free of saliva were collected with a rumen vacuum sampler from 20 cows (10 from each treatment) at $1 \mathrm{~h}$ before feeding $(0900 \mathrm{~h})$ and $3 \mathrm{~h}$ after feeding $(1300 \mathrm{~h})$. The $\mathrm{pH}$ values were determined immediately by a portable $\mathrm{pH}$ meter (M. R. C. Ltd., Holon, Israel). 


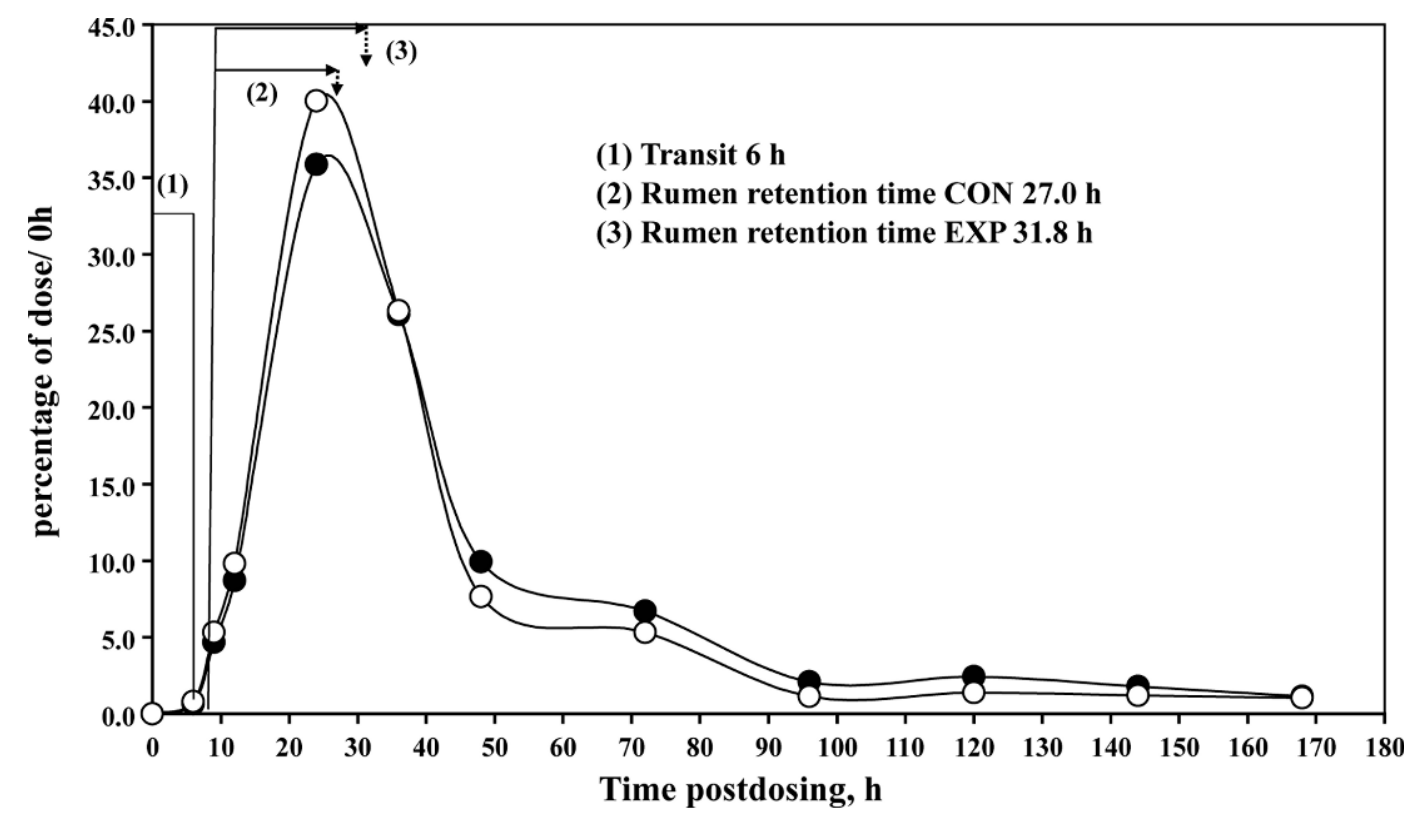

Figure 1. Digesta kinetics for cows fed the $\operatorname{EXP}(\bullet)$ and CON $(\bigcirc)$ TMR. EXP $=$ experimental TMR containing $12.8 \%$ NDF of roughage origin; CON $=$ control TMR containing $18.7 \%$ NDF of forage origin.

\section{Pattern of Rumination}

All cows were equipped with rumination tag-monitoring systems that measured the duration of rumination (min/d) over 60 DIM. Commercial tags (Hi-Tag, SCR Engineers, Netanya, Israel), which are routinely used in Israeli herds, were used for this measurement. The rumination data were automatically downloaded after each milking, stored in the herd computer, and analyzed by special software. The basic principal of the rumination time was measured by analyzing the isolated chewing sounds during rumination, excluding the sounds related to eating. Data was stored in 2-h cells in 2-min resolution. Rumination data were collected between $\mathrm{d}-21$ prepartum and 60 DIM. All cows were fed the same close-up diet ( $13.5 \%$ soybean meal, $18.4 \%$ corn grain, $10.5 \%$ barley grain, $56.7 \%$ wheat hay, and $0.9 \%$ trace mineral and vitamin mixture, on a DM basis) until calving.

\section{Statistical Analyses}

Comparisons between the 2 groups of cows fed the 2 TMR with respect to individual feeding behavior, DMI, rumination, and milk performance data were carried out according to the repeated measurement PROC MIXED model (SAS Institute, 1996) and are presented in Tables 2, 3, and 4 as the daily means. Tukey's test (SAS Institute, 1996) was used for comparisons between means.
Differences between the 2 TMR (12 weekly composites of each TMR) with respect to composition, in vivo and in vitro digestibility, and rate of particle passage were tested for significance by ANOVA using JMP-5 software (SAS Institute, 1996). Tukey's test (SAS Institute, 1996) was used for comparisons between means.

\section{RESULTS AND DISCUSSION}

\section{Eating Behavior, Rumination, Digestibility, and Rate of Particles Passage}

The 2 diets in this study differed in content of roughage and roughage NDF (23.5 vs. $35.0 \%$, and 12.8 vs. $18.7 \%$ in the EXP and CON TMR, respectively; Tables 1 and 2). This characteristic was expressed in a different particle size distribution in the 2 diets. In the CON TMR, a higher proportion of particles was retained in the 19-mm sieve of the PSPS, and a smaller proportion was retained in the bottom pan $(<8-\mathrm{mm}$ sieve $)$ as compared with the EXP TMR $(P=0.05$; Table 2 ). Thus, the EXP TMR contained $17.0 \%$ less peNDF than the CON TMR (11.7 vs. $14.1 \%$ of DM, respectively, $P=0.05$ ). The inclusion of soyhulls as a partial roughage replacement did not affect $\mathrm{OM}, \mathrm{CP}$, and ether extract content of the EXP TMR but did significantly influence NDF potential digestibility and content. This was reflected in a $6.2 \%$ increase in the in vitro NDF digestibility of EXP TMR as compared with the CON TMR $(P=0.01$; Table 2). It should be noted that the in vitro NDF degradabilities of corn silage, vetch 
Table 2. Chemical composition, in vitro digestibility, and particle size distribution in the $2 \mathrm{TMR}^{1}$

\begin{tabular}{lcccc}
\hline Item & EXP & CON & SEM & $P$-value \\
\hline Chemical composition & & & & \\
DM, \% of wet TMR & 70.9 & 70.8 & 0.50 & NS \\
Roughage NDF, \% of DM & 12.8 & 18.7 & & \\
Roughage, \% of DM & 23.5 & 35.0 & & \\
OM, \% of DM & 92.4 & 92.3 & 0.20 & $\mathrm{NS}$ \\
CP, \% of DM & 17.1 & 17.0 & 0.10 & $\mathrm{NS}$ \\
Ether extract, \% of DM & 4.6 & 4.5 & 0.10 & $\mathrm{NS}$ \\
NDF, \% of DM & 31.4 & 32.5 & 0.02 & 0.02 \\
In vitro DM digestibility, \% & 79.7 & 77.5 & 0.39 & 0.01 \\
In vitro NDF digestibility, \% & 65.4 & 61.6 & 0.67 & 0.01 \\
PSPS, \% of DM retained on sieves & & & & \\
Upper sieve, particles >19 mm & 9.9 & 18.1 & 1.86 & 0.03 \\
Middle sieve, particles >8 mm & 27.2 & 25.3 & 1.07 & $\mathrm{NS}$ \\
Bottom pan, particles <8 mm & 62.9 & 56.6 & 1.30 & 0.02 \\
peNDF $>$ \% $\%$ of DM & 11.7 & 14.1 & 0.54 & 0.05 \\
\hline
\end{tabular}

${ }^{1} \mathrm{EXP}=$ experimental TMR containing $12.8 \% \mathrm{NDF}$ of roughage origin; $\mathrm{CON}=$ control $\mathrm{TMR}$ containing $18.7 \%$ NDF of forage origin.

${ }^{2}$ PSPS $=$ particle size distributions, measured using the new Penn State Particle Separator (Lammers et al., 1996).

${ }^{3}$ peNDF $=$ physically effective NDF (determined as the proportion of DM retained by the 19- and the 8-mm sieves of the PSPS multiplied by dietary NDF; Yang et al., 2002).

hay, wheat hay, and soyhulls were $68.3,49.7,50.8$, and $83.0 \%$, respectively, and their NDF degradability rates were $4.6,6.48,4.32$, and $4.9 \% / \mathrm{h}$, respectively. These data showed the potential of NDF degradability in vitro; however, the in vivo pattern of digestion of these substrates might also have depended on their peNDF and the interaction with other ingredients of the TMR that affect their actual retention time in the rumen and their rate of passage.

These differences in TMR ingredients and their chemical compositions (Tables 1 and 2), were expressed in a greater intake per meal (by $13.3 \%, P=0.03$ ), a higher rate of meal consumption (by $23.2 \%, P=0.02$ ), a similar number of meals per day (7.92 and 8.35), a shorter daily eating duration (by $13 \%, P=0.05$ ), and a greater total daily DMI (by $7.2 \%, P=0.02$ ) in the
EXP cows as compared with the CON cows (Table 3 ). Similar effects on rate of eating and daily DMI were obtained in previous studies that used soyhulls as a partial roughage replacement in TMR of midlactating cows (Miron et al., 2003, 2008; Adin et al. 2008). Improvement of DMI in a similar feeding system was shown also by Weidner and Grant (1994).

It is well accepted in the literature that the main factor that restricts voluntary DMI by lactating cows is high dietary NDF content, which reduces DM digestibility of the diet (Van Soest, 1994). When DM digestibility values in the diets of lactating cows are below $67 \%$, the rumen fill mechanism is predominant in determining DMI, whereas above this digestibility value, the chemostatic regulation by blood metabolites is predominant (Van Soest, 1994). In both diets in this study,

Table 3. Eating behavior of cows fed the $2 \mathrm{TMR}^{1}$

\begin{tabular}{lcccc}
\hline Item & EXP & CON & SEM & $P$-value \\
\hline Meals, n/d & 7.92 & 8.35 & 0.19 & $\mathrm{NS}$ \\
Meal intake, $\mathrm{kg}$ of DM/meal & 3.40 & 3.00 & 0.05 & 0.03 \\
Meal duration, min/meal & 33.0 & 35.9 & 0.45 & 0.04 \\
Rate of meal intake, g of DM/min & 103 & 83.6 & 1.47 & 0.02 \\
Daily eating duration, min & 261 & 300 & 6.46 & 0.05 \\
DMI, $\mathrm{kg} / \mathrm{d}$ & 26.9 & 25.1 & 0.38 & 0.02 \\
NDF intake, $\mathrm{kg} / \mathrm{d}$ & 8.4 & 8.2 & 0.12 & $\mathrm{NS}$ \\
Roughage intake, $\mathrm{kg}$ of DM/d & 6.32 & 8.79 & 0.11 & 0.01 \\
Roughage NDF intake, $\mathrm{kg} / \mathrm{d}$ & 3.43 & 4.69 & 0.11 & 0.01 \\
Nonroughage NDF intake, $\mathrm{kg}$ of DM/d & 4.97 & 3.53 & 0.07 & 0.01 \\
peNDF intake, ${ }^{2} \mathrm{~kg} / \mathrm{d}$ & 3.15 & 3.54 & 0.05 & 0.01 \\
\hline
\end{tabular}

${ }^{1} \mathrm{EXP}=$ experimental TMR containing $12.8 \% \mathrm{NDF}$ of roughage origin; $\mathrm{CON}=$ control TMR containing $18.7 \%$ NDF of forage origin.

${ }^{2}$ peNDF $=$ physically effective NDF (determined as the proportion of DM retained by the 19- and the 8-mm sieves of the new Penn State Particle Separator multiplied by dietary NDF; Yang et al., 2002). 
Table 4. Digestibility, pattern of rumination, and particle flow in dairy cows fed the $2 \mathrm{TMR}^{1}$

\begin{tabular}{|c|c|c|c|c|}
\hline Item & EXP & $\mathrm{CON}$ & SEM & $P$-value \\
\hline DM in vivo digestibility, $\%$ & 62.5 & 59.6 & 0.71 & 0.03 \\
\hline NDF in vivo digestibility, $\%$ & 49.7 & 40.5 & 1.65 & 0.01 \\
\hline Rumination ${ }^{2} \mathrm{~min} / \mathrm{d}$ & 428.3 & 482.6 & 13.1 & 0.01 \\
\hline Rumination per $\mathrm{kg}$ of DM roughage intake, ${ }^{2} \mathrm{~min} / \mathrm{d}$ & 67.8 & 54.9 & 1.74 & 0.02 \\
\hline Rumination per $\mathrm{kg}$ of $\mathrm{peNDF},{ }^{2} \mathrm{~min} / \mathrm{d}$ & 136.0 & 136.3 & 3.91 & NS \\
\hline Rumen pH & 6.67 & 6.57 & 0.05 & NS \\
\hline \multicolumn{5}{|l|}{ Flow of particles ${ }^{3}$} \\
\hline Transit time, $\mathrm{h}$ & 6.1 & 6.0 & 0.29 & NS \\
\hline Rumen mean retention time, $\mathrm{h}$ & 31.8 & 27.0 & 1.19 & 0.03 \\
\hline Lower tract mean retention time, $\mathrm{h}$ & 127.4 & 133.0 & 1.40 & 0.04 \\
\hline Rate of passage-rumen, $\% / \mathrm{h}$ & 3.70 & 4.42 & 0.18 & 0.04 \\
\hline Rate of passage-lower tract, $\% / \mathrm{h}$ & 1.53 & 2.04 & 0.36 & NS \\
\hline
\end{tabular}

${ }^{1} \mathrm{EXP}=$ experimental TMR containing $12.8 \%$ NDF of roughage origin; CON $=$ control TMR containing $18.7 \%$ NDF of forage origin.

${ }^{2}$ Parameters related to rumination were measured for only 60 DIM. peNDF $=$ physically effective NDF (determined as the proportion of DM retained by the 19- and the 8-mm sieves of the new Penn State Particle Separator multiplied by dietary NDF; Yang et al., 2002).

${ }^{3}$ Parameters were calculated using data from Figure 4 based on the natural logarithms of fecal Cr concentrations against time as described by Ben-Ghedalia and Miron (1984).

the in vivo DM digestibility was below $67 \%$ (Table 4); therefore, the gut fill mechanism seemed to dominate. In this study, the increase in DMI was not only related to the lower NDF content of the EXP diet, but also might be related mainly to the quality of the dietary NDF ingested. The EXP TMR contained a higher level (by $34.8 \%$; Table 2) of readily digestible nonroughage NDF components (Miron et al., 2001a) and a lower level of peNDF (by $17 \%, P=0.05$; Table 2) as compared with the CON diet. This difference resulted in higher NDF digestibility in vivo (by $22.7 \%, P=0.01$; Table 4) and a reduced rumination time (by $11.3 \%, P=0.01$; Table 4) in the EXP cows as compared with the CON cows. Thus, more space for additional DM and NDF ingestion was created within the rumen of the EXP cows as compared with the CON cows. This indeed was reflected in a higher DMI per meal (by 13.3\%, $P=$ 0.03 ) and a higher rate of meal intake (by $23.2 \%, P=$ 0.02 ; Table 3 ) by the EXP cows as compared with the CON cows.

The differences in TMR composition also affected the in vivo DM and NDF digestibility, which was higher by 4.9 and $22.7 \%$, respectively $(P=0.03$ and $P=0.01$; Table 4) in the EXP cows as compared with the CON cows. Possible explanations for this advantage in digestibility might be 1) greater intake (by $40.8 \%, P=$ 0.01: Table 3) of NDF from soyhulls by the EXP cows, because soyhull NDF is more digestible than roughage NDF (Miron et al., 2003); 2) the decreased average particle size of the EXP diet, which might have increased the surface area available for the attachment of rumen cellulolytic bacteria (Miron et al., 2001) and may have further enhanced NDF digestibility in the rumen; 3) a longer rumen retention time of roughage particles in the EXP cows (by $17.8 \%, P=0.03$; Table 4), which enabled better NDF digestion; and 4) longer rumination per kilogram of roughage ingested by the EXP cows (by $23.5 \%, P=0.02$; Table 4 ), which improved dietary NDF digestibility. The longer retention time in the rumen and the better availability for further degradation by rumen cellulolytic bacteria of the roughage particles, accompanied by appropriate rumen $\mathrm{pH}$ values (6.67; Table 4), enabled better conditions for NDF digestion in the rumen of the EXP cows as compared with the CON cows. This might explain how the EXP cows succeeded in overcoming the possible inhibitory effect on NDF digestion that usually follows an increase in DMI (Van Soest, 1994).

It should be noted that the DM and NDF digestibility values in vivo (Table 4) were lower for each TMR than the corresponding values of potential of digestion (in vitro measurement; Table 2). The gap between the 2 diets with respect to $\mathrm{DM}$ in vivo digestibility was similar to the gap obtained in vitro (4.9 vs. $2.8 \%$ ), whereas the gap between the $2 \mathrm{TMR}$ with respect to $\mathrm{NDF}$ in vivo digestibility values was much higher than the gap in vitro (22.7 vs. $6.2 \%$, respectively; Tables 2 and 4). These differences between measurements probably originated from factors such as level of DMI, level of peNDF intake, rumination time, and rate of passage from the rumen of roughage particles, as discussed above, which are not relevant to the in vitro system.

The rumination time of the EXP cows was shorter by $54.3 \mathrm{~min} / \mathrm{d}$ than that of the CON cows $(P=0.01)$, and this was probably related to the difference of $12.4 \%$ in peNDF intake of the CON diet as compared with the 


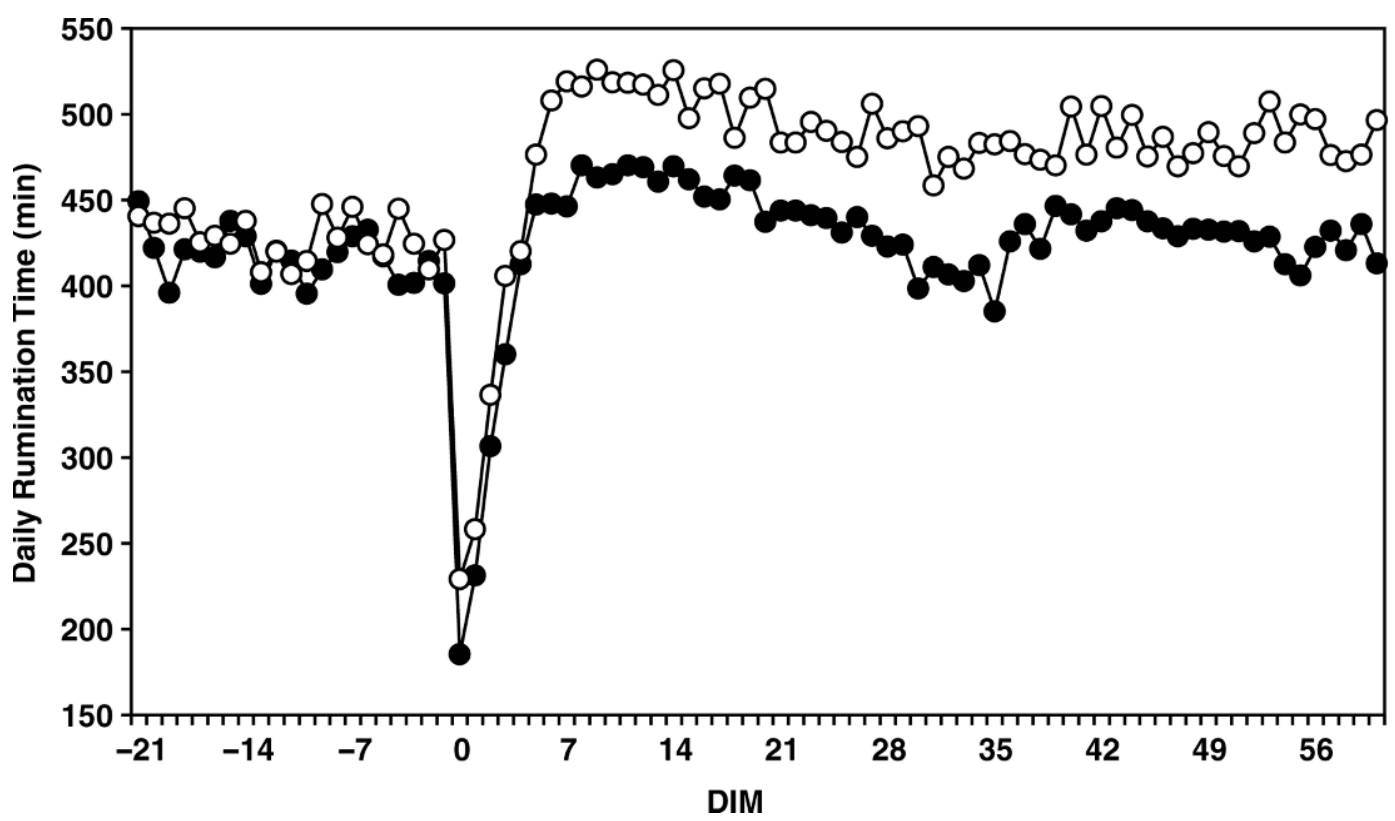

Figure 2. Daily rumination time (min) from -21 d precalving to 60 DIM in the 2 dietary treatments $(\mathrm{EXP}, \bullet$; CON, $\mathrm{O})$. EXP $=$ experimental TMR containing $12.8 \%$ NDF of roughage origin; CON = control TMR containing $18.7 \%$ NDF of forage origin.

EXP diet $(P=0.01$; Table 3$)$. This relationship is well established in the literature (Yang and Beauchemin, 2006).

A comparison between the data on rumination time per kilogram of peNDF ingested in this study (136 $\mathrm{min} / \mathrm{kg}$ of peNDF ingested in both treatments; Table
4) and data provided in the literature (Kononoff et al., 2003; Beauchemin and Yang 2005; Zebeli et al., 2007; Teimouri Yansari et al., 2004) showed a general negative correlation $\left(\mathrm{r}^{2}=-0.75\right)$ between kilograms of peNDF ingested and rumination time per kilogram of peNDF consumed. A possible explanation for this trend

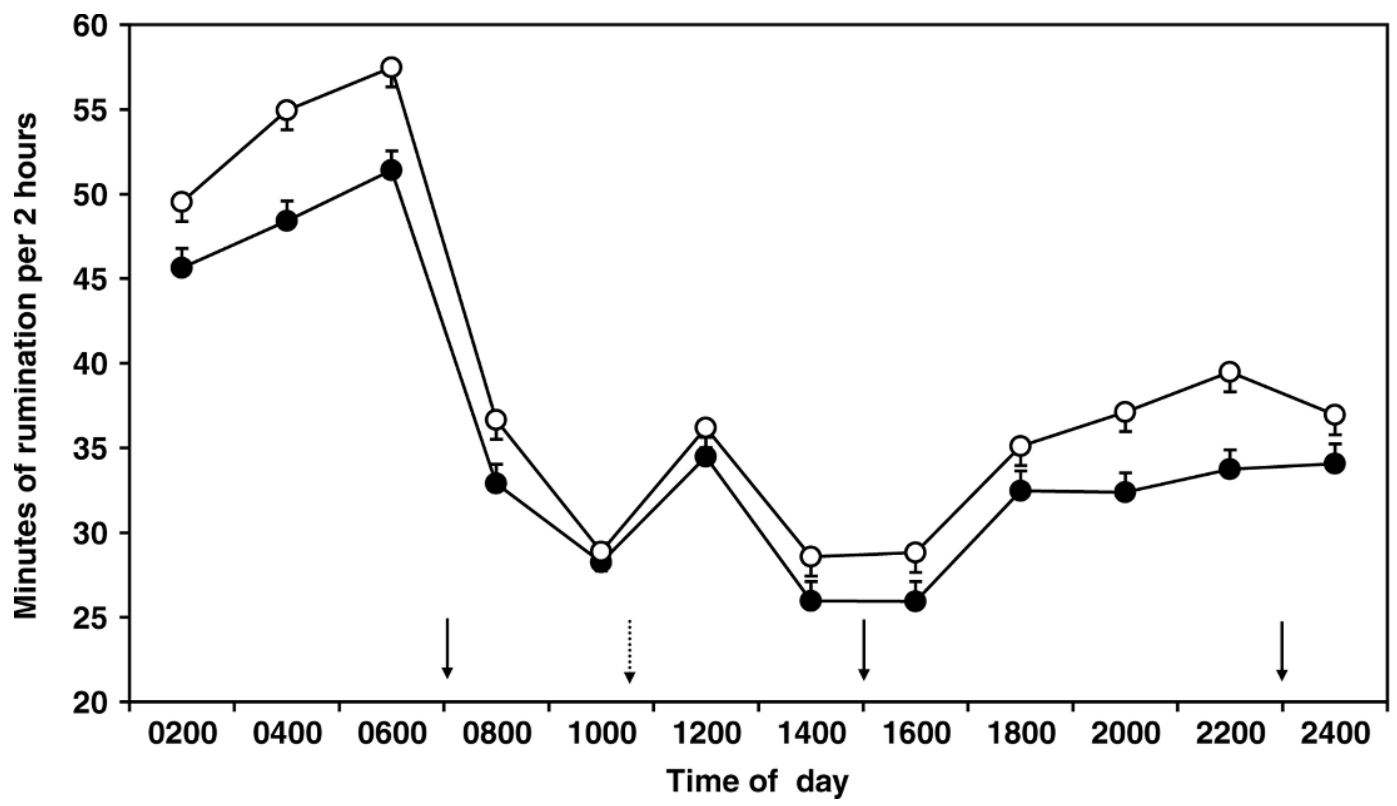

Figure 3. Pattern of rumination distribution over $24 \mathrm{~h}$ of an average day for cows fed the EXP $(\bullet)$ and CON $(O)$ TMR. The dotted arrow indicates the time a fresh TMR was dispensed, and the solid arrows indicate the return of cows from milking. EXP = experimental TMR containing $12.8 \% \mathrm{NDF}$ of roughage origin; $\mathrm{CON}=$ control TMR containing $18.7 \% \mathrm{NDF}$ of forage origin. 


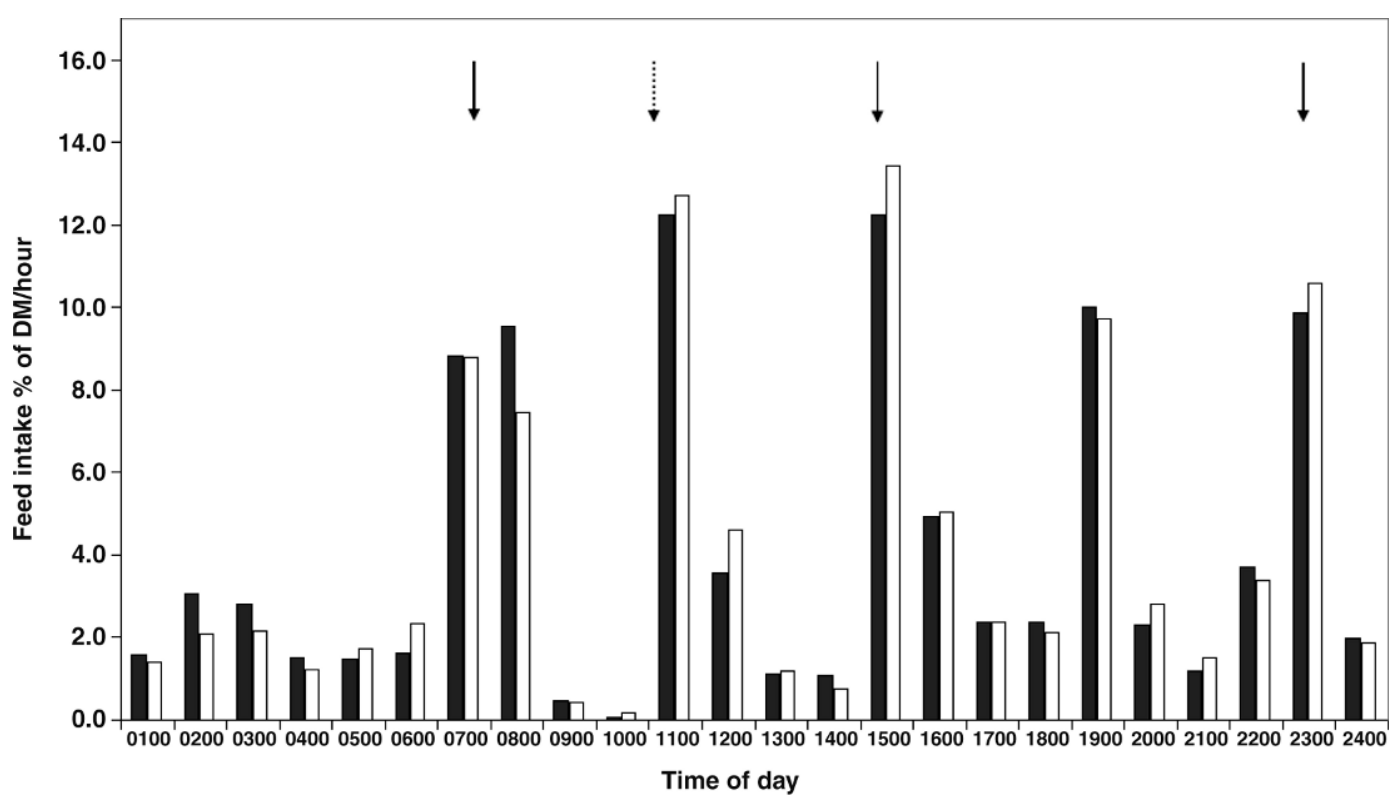

Figure 4. Distribution of the diurnal pattern of feed intake (\% of DM/h) over $24 \mathrm{~h}$ in an average day in cows fed the EXP (solid bars) and CON (open bars) TMR. The dotted arrow indicates the time a fresh TMR was dispensed, and the solid arrows indicate the return of cows from milking. EXP = experimental TMR containing $12.8 \% \mathrm{NDF}$ of roughage origin; CON = control TMR containing $18.7 \% \mathrm{NDF}$ of forage origin.

could be the relationship between rate of particle passage (based on the particle kinetics data given in Figure 1 and summarized in Table 4) and rumination found in this study (Table 4). The greater peNDF intake (by $12.4 .0 \%$ ) in the CON cows resulted in a higher rate of particle passage in the rumen (by $19.5 \%, P=0.04$; Table 4) and a lower rumination time per kilogram of $\mathrm{DM}$ of roughage ingested (by $19 \%, P=0.02$; Table 4) as compared with the EXP cows, and this might explain the negative correlation between peNDF intake and length of rumination time per kilogram of peNDF ingested.

The daily rumination time of both dietary groups was similar for the last $21 \mathrm{~d}$ precalving when the cows were fed the same close-up diet (between 400 to 450 $\mathrm{min} / \mathrm{d}$; Figure 2). However, immediately after calving, beginning from 3 DIM, a consistent difference in rumination time, with an advantage for the CON cows, was created and preserved during the entire experiment (Figure 2), with averages of 428 vs. $483 \mathrm{~min} / \mathrm{d}$ in the EXP and CON diets, respectively (Table 4). These rumination times, which were measured in this study by an automatic system (SCR Engineers tags) fell within the range of 340 to $540 \mathrm{~min} / \mathrm{d}$ found in the literature for high-producing cows with voluntary DMI above 25 $\mathrm{kg} / \mathrm{d}$ (Kononoff et al., 2003; Teimouri Yansari et al., 2004; Beauchemin and Yang, 2005).

A consistent difference in rumination time between the 2 TMR was also noted in the rumination distribution pattern over $24 \mathrm{~h}$ in an average day for cows fed the 2 diets (Figure 3). Rumination peaks occurred mostly late at night and in the early morning hours, and at approximately an hour after a fresh TMR was dispensed and when cows returned from milking. Data on the pattern of feed intake over the hours in an average day (Figure 4) showed eating peaks every 3 to $4 \mathrm{~h}$ from the morning to the late evening milking. It is possible that these peaks also followed stimulation events, such as the dispensing of food (1030 h), cows returning from milking $(0700,1500$, and $2300 \mathrm{~h})$, and automatic illumination of the lights along the feeding lane (1900 h). While eating, cows are unable to ruminate (Van Soest, 1994); a comparison between Figures 3 and 4 shows that the rumination peaks indeed appeared at least an hour after the eating peaks during the daytime, and also during the nighttime hours (2400 to $0600 \mathrm{~h}$ ) when cows were not eating. A similar distribution of eating peaks was also demonstrated in previous studies (Miron et al., 2003; Adin et al., 2008).

\section{Milk Production and BW Changes}

The higher DM and NDF in vivo digestibility of cows fed the EXP TMR consequently revealed a greater DMI (Table 3) and was reflected in a concomitant $7.4 \%$ increase in milk production $(P=0.01)$ and a $9.2 \%$ increase in FCM yield $(P=0.05)$ in the EXP cows (Table $5)$ as compared with the CON cows. It should be noted that the efficiency of TMR utilization for FCM production in cows fed the EXP TMR was not significantly 
Table 5. Average milk performance in cows fed the 2 dietary treatments ${ }^{1}$ for 90 DIM

\begin{tabular}{lcccc}
\hline Item & EXP & CON & SEM & $P$-value \\
\hline Milk yield, $\mathrm{kg} / \mathrm{d}$ & 52.1 & 48.5 & 0.71 & 0.01 \\
Milk fat yield, kg/d & 1.77 & 1.65 & 0.04 & $\mathrm{NS}$ \\
Milk protein yield, kg/d & 1.59 & 1.53 & 0.03 & $\mathrm{NS}$ \\
$4 \%$ FCM, kg/d & 42.6 & 39.0 & 0.92 & 0.05 \\
Production efficiency, kg of FCM/kg of DMI & 1.58 & 1.55 & 0.03 & $\mathrm{NS}$ \\
BW change, $\mathrm{kg} / \mathrm{d}$ & -0.612 & -0.575 & 0.052 & $\mathrm{NS}$ \\
\hline
\end{tabular}

${ }^{1} \mathrm{EXP}=$ experimental TMR containing $12.8 \%$ NDF of roughage origin; CON = control TMR containing $18.7 \%$ NDF of forage origin.

higher than that of the CON cows (1.58 vs. $1.55 \mathrm{~kg}$ of $\mathrm{FCM} / \mathrm{kg}$ of DMI; Table 5$)$ despite the $4.9 \%$ increase in DM digestibility of the EXP TMR $(P=0.03$; Table 4$)$. This finding suggests that the improvement in digestibility of the EXP cows was not manifested directly in an enhancement of the efficiency of feed utilization for milk production, but increased the voluntary DMI. In previous studies with midlactation milking cows fed diets with soyhulls as a partial roughage replacement (Adin et al., 2008; Miron et al., 2008), we found a similar trend: an increase in DM and NDF potential digestibility (in vitro) of the EXP TMR was expressed mostly in increased DMI, but not in improved efficiency of feed utilization for milk production. This finding supports the predominant importance of DMI in determining milk production by lactating cows (Van Soest, 1994).

The nutritional manipulation used in the present study improved the in vivo digestibility of dietary DM and NDF, leading to an increase of voluntary DMI, and the outcome was improved milk performance. Notwithstanding, several nutritional manipulations suggested in the literature to improve milk production in early lactation were less effective in increasing either in vivo digestibility or DMI. Supplementation of rumen-inert fat (partially hydrogenated tallow) failed to increase either milk yield or DMI (Salfer et al., 1995). Supplementation of drenched fat (Ca soaps of palm oil fatty acids) during the first 3 wk of lactation resulted in reducing the milk yield and DMI (Pickett et al., 2003), whereas supplementation of Ca salts of fatty acids improved milk and FCM yields but reduced DMI (Schneider et al., 1988). Addition of sucrose at $1.5 \%$ of TMR did not enhance DMI over the first $12 \mathrm{wk}$ postpartum (Nombekela and Murphy, 1995). Administration of propylene glycol did not improve DMI or milk yield during the first $3 \mathrm{wk}$ postpartum (Pickett et al., 2003).

Despite the increase in milk and FCM production of the EXP cows, there were no significant differences between the 2 groups with respect to BW changes (Table 5). It is suggested that the higher DMI of the EXP cows supplied all the required energy and metabolites for higher milk production; therefore, cows were not compelled to mobilize missing energy sources from body reservoirs, as implied by the similar BW changes of the 2 groups.

\section{CONCLUSIONS}

This study demonstrated that feeding lactating cows during the first 90 DIM with soyhulls as a partial roughage replacer increased voluntary DMI by $7.2 \%$ and in vivo DM and NDF digestibility by 4.9 and $22.7 \%$, respectively, as compared with CON cows. This was reflected in higher milk and FCM yields (by 7.4 and $9.2 \%$, respectively) in the EXP cows as compared with the CON cows.

\section{ACKNOWLEDGMENTS}

We express our appreciation to the Volcani Center (Bet-Dagan, Israel) dairy farm team and to Zwi Sarid and his team from Yavne Feeding Center (Kibbutz Yavne, Israel) for their efforts in feedings the cows and to Doron Bar from SCR Engineers, for interpretation of the rumination data. This study was supported by research grant number 362-071-06 of the Israeli Milk Council (Rishon-Lezion, Israel).

\section{REFERENCES}

Adin, G., R. Solomon, E. Shoshani, I. Flamenbaum, M. Nikbachat, E. Yosef, A. Zenou, I. Halachmi, A. Shamay, A. Brosh, S. J. Mabjeesh, and J. Miron. 2008. Heat production, eating behavior and milk yield of lactating cows fed two rations differing in roughage content and digestibility under heat load conditions. Livest. Sci. 19:145-153.

AOAC. 2001. Official Methods of Analysis. Assoc. Off. Anal. Chem., Washington, DC.

Beauchemin, K. A., and W. Z. Yang. 2005. Effects of physically effective fiber on intake, chewing activity, and ruminal acidosis for dairy cows fed diets based on corn silage. J. Dairy Sci. 88:21172129 .

Ben-Ghedalia, D., and J. Miron. 1984. The digestion of total and cell wall monosaccharides of alfalfa by sheep. J. Nutr. 114:880-887.

Kononoff, P. J., A. J. Heinrichs, and H. A. Lehman. 2003. The effect of corn silage particle size on eating behavior, chewing activities, and rumen fermentation in lactating dairy cows. J. Dairy Sci. $86: 3343-3353$ 
Lammers, B. P., D. R. Buckmaster, and A. J. Heinrichs. 1996. A simple method for the analysis of particle size of forage and total mixed ratios. J. Dairy Sci. 79:922-928.

Lippke, H., W. C. Ellis, and B. F. Jacobs. 1986. Recovery of indigestible fiber from feces of sheep and cattle on forage diets. J. Dairy Sci. 69:403-412.

Mertens, D. R., and J. R. Loften. 1980. The effect of starch on forage fiber digestion kinetics in vitro. J. Dairy Sci. 63:1437-1446.

Miron, J., G. Adin, R. Solomon, M. Nikbachat, A. Zenou, A. Shamay, A. Brosh, and S. J. Mabjeesh. 2008. Heat production and retained energy in lactating cows held under hot summer conditions with evaporative cooling and fed two rations differing in roughage content and in vitro digestibility. Animal 2:843-848.

Miron, J., D. Ben-Ghedalia, and M. Morrison. 2001. Invited Review: Adhesion mechanisms of rumen cellulolytic bacteria. J. Dairy Sci. 84:1294-1309.

Miron, J., E. Yosef, and D. Ben-Ghedalia. 2001a. Composition and in vitro digestibility of monosaccharide constituents of selected byproduct feeds. J. Agric. Food Chem. 49:2322-2326.

Miron, J., E. Yosef, E. Maltz, and I. Halachmi. 2003. Soybean hulls as a replacement of forage neutral detergent fiber in total mixed rations of lactating cows. Anim. Feed Sci. Technol. 106:21-28.

NRC. 2001. Nutrient Requirements of Dairy Cattle. 7th ed. Natl. Acad. Press, Washington, DC.

Nombekela, S. W., and M. R. Murphy. 1995. Sucrose supplementation and feed of dairy cows in early lactation. J. Dairy Sci. 78:880885 .

Pickett, M. M., M. S. Piepenbrink, and T. R. Overton. 2003. Effects of propylene glycol or fat drench on plasma metabolites, liver composition, and production of dairy cows during the periparturient period. J. Dairy Sci. 86:2113-2121.

Salfer, J. A., J. G. Linn, D. E. Otterby, W. P. Hansen, and D. G. Johnson. 1995. Early lactation responses of holstein cows fed a rumen-inert fat prepartum, postpartum, or both. J. Dairy Sci. $78: 368-377$.

SAS Institute. 1996. SAS/STAT Software Changes and Enhancements. SAS Inst., Cary, NC.

Schneider, P., D. Sklan, W. Chalupa, and D. S. Kronfeld. 1988. Feeding calcium salts of fatty acids to lactating cows. J. Dairy Sci. 71:2143-2150.

Teimouri Yansari, A., R. Valizadeh, A. Naserian, D. A. Christensen, P. Yu, and F. Eftekhari Shahroodi. 2004. Effects of alfalfa particle size and specific gravity on chewing activity, digestibility, and performance of Holstein dairy cows. J. Dairy Sci. 87:3912-3924.

Tilley, J. M., and R. M. Terry. 1963. A two stage technique for the in vitro digestion of forage crops. J. Br. Grassl. Soc. 18:104-111.

Van Soest, P. J. 1994. Nutritional Ecology of the Ruminant. Cornell University Press, Ithaca, NY.

Van Soest, P. J., J. B. Robertson, and B. A. Lewis. 1991. Methods for dietary fiber, neutral detergent fiber, and non-starch polysaccharides in relation to animal nutrition. J. Dairy Sci. 74:3583-3597.

Weidner, S. J., and R. J. Grant. 1994. Soyhulls as a replacement for forage fiber in diets for lactating dairy cows. J. Dairy Sci. 77:513521

Yang, W. Z., and K. A. Beauchemin. 2006. Physically effective fiber: Method of determination and effects on chewing, ruminal acidosis, and digestion by dairy cows. J. Dairy Sci. 89:2618-2633.

Yang, W. Z., K. A. Beauchemin, and L. M. Rode. 2002. Effects of particle size of alfalfa-based dairy cow diets on site and extent of digestion. J. Dairy Sci. 85:1958-1968.

Zebeli, Q., M. Tafaj, I. Weber, J. Dijkstra, H. Steingass, and W. Drochner. 2007. Effects of varying dietary forage particle size in two concentrate levels on chewing activity, ruminal mat characteristics, and passage in dairy cows. J. Dairy Sci. 90:1929-1942. 